Article

\title{
Presenting Health Status in Children Using a Radar Plot
}

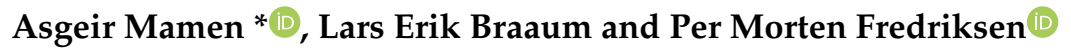 \\ School of Health Sciences, Kristiania University College, Prinsensgate 7-9, 0152 Oslo, Norway; \\ larserik.braaum@kristiania.no (L.E.B.); permorten.fredriksen@kristiania.no (P.M.F.) \\ * Correspondence: asgeir.mamen@kristiania.no
}

Received: 27 March 2020; Accepted: 21 April 2020; Published: 23 April 2020

\begin{abstract}
Background: To try out the feasibility of presenting the health status of children 6 to 12 years old by using radar plots. Methods: With data from the Health Oriented Pedagogical Project (HOPP) we have described the health status for 1340 children aged 6 to 12 years. We collected or calculated: stature, body mass, waist circumference, waist to height ratio, high density lipoprotein (HDL) and total cholesterol concentration, blood pressure, accelerometer assessed physical activity, endurance interval running performance, and quality of life. Pertinent variables were presented through a radar plot for both individual cases and groups. Results: The boys showed better endurance and recorded more moderate to vigorous physical activity than the girls. The activity level dropped from age 6 to age 12 for both sexes. The girls showed a lower systolic blood pressure compared with boys. Self-rated quality of life was high among boys and girls. Conclusions: This cohort showed good health and the radar plot made it easy to visualise health status for groups and individuals.
\end{abstract}

Keywords: health; physical activity; exercise

\section{Introduction}

The global burden of disease involves a variety of factors with the ability to increase the risk of illness. Occurring alone, each factor poses a potential threat to health, while in combination, the magnitude of risk increases significantly for chronic illness and early fatal death. It is well documented that such risk factors are established in childhood, partly due to genetic factors but are also due to lifestyle-related behaviour. In the case of children, this is mainly associated with parental choice of lifestyle. As an example, it has been discovered that atherosclerosis can be established in young children, as found in the Bogalusa Heart Study [1].

Giving an accurate description of health status can be difficult. During the Crimean war in the 1850s, Florence Nightingale pioneered this presentation by using coxcomb graphs to illustrate the grim health situation in military hospitals [2]. Today there are several graphs available for the researcher. A radar plot, invented by Georg von Mayr, 1877 [3] can be viewed as a connected line graph, thereby reducing the size of the plot. The circular form makes it easy to compare different entities, especially if there is an agreed sequence of the variable, and, as we have done, included a reference line. It has been found useful in social sciences and health sciences to illustrate development or differences. Noirhomme-Fraiture suggests using such a plot for large data analysis [4]. The plot is also known as a Spider Plot or Star Plot among other names.

Although to date, radar plots have not been widely employed in health sciences, they demonstrate potential as an effective means to visualise multiple health related variables in one plot [5]. This is useful as noted in recent conference proceedings [6] where Ordóñez et al. discuss several plots, among them 2D and 3D radar plots for presentation of data in an Intensive Care Unit. Another example is a study using radar plots to describe changes in European Union (EU) alcohol policy [7], showing the 
broad spectre of data such a plot can handle. The present study demonstrates the potential usefulness of radar plots in visualising health related variables, with data representing a large number of participants and comprising carefully chosen and clinically relevant variables. Despite this, it should be noted that the sample in the present study does include use of some self-report data from children which should be considered a limitation.

However, waist to height ratio (WHtR) does not take into account other variables of importance for good health, such as blood pressure, blood lipids, and social variables such as quality of life. There would therefore seem to be a need for a more detailed description of children's health status; however, one might ask why healthy children need a health profile. In view of the growing number of children with lifestyle-related risk factors like overweight, inactivity, and low quality of life, an easy to use and comprehensible health profile instrument may be of help when mapping both status quo and intervention effects. A health profile that provides full details of the physical and mental health of an individual and a population would be of immense help for both the public health care system and the individual general practitioner. If the health profile also makes it easy to perceive changes in an intuitive way, we believe most health care personnel would be willing to use such a profile.

A comprehensive overview of an individual's physical and mental state may be one tool to counteract some of the health problems facing a large part of the world's population. To create such an overview, several variables may be perceived as important for constructing a health profile. Physical variables, such as anthropometric data, physical performance measures and physical activity level, and medical variables, such as blood pressure and results of various blood tests, are all important. In addition, softer data such as quality of life, emotions, self-esteem, friendship, nutrition, and ability to concentrate could also form part of such a profile.

To prevent lifestyle-related diseases in childhood and adolescence, an individual health profile is crucial for revealing changes. Such a profile should be related to established reference values for the age group and gender and possibly be standardised with respect to variables and units.

The aim of this study is to present a suggestion for a health profile for children that we believe is easy to interpret and that provides a more comprehensive synopsis of essential factors for health than a single measurement.

\section{Materials and Methods}

\subsection{Sample}

The study population was recruited from the Health Oriented Pedagogical Project (HOPP), a controlled longitudinal school-based physical activity intervention programme. The project is registered as a clinical trial (ClinicalTrials.gov Identifier: NCT02495714) and accepted by the Regional Ethical Committee (REC Identifier 2014/2064) and is described in detail elsewhere [8] Shortly, the children of the elementary schools in Horten Municipality $(n=7)$ were given 45 min of extra physical activity in connection with teaching activities each day. The evaluation of the effect of this intervention continues until 2021 with yearly collection of health, academic, and sociological data from the participating children. As control schools, two schools in the Greater-Oslo area participated, $\mathrm{N}=2297$. Informed consent from parents/guardians was obtained before the data collection started. The children can leave this evaluation project at any time, but not the school programme as that is the mandatory school programme for the public schools in the municipality. Parents and children aged 6-12 years from nine schools received an invitation to participate in the project. Of a population of 2816 children, 2297 children $(82 \%)$ were allowed to participate by their parents. The children were given the opportunity to opt out of the blood sample test, while participating in the other test procedures, and $58.4 \%$ of the children ( $n=1340, n=650$ girls) provided blood samples. Age was defined as age on the test date. The ethnicity of the children was not recorded; however, most of the children were of Caucasian origin. The variables were collected in spring 2015, which are the baseline results. 


\subsection{The Radar Plot}

As a radar plot can handle several variables in a comparable state, such a plot was chosen to present the health profile. To facilitate comparison, variables were presented as percentages of the reference values. To provide a uniform view, the scales were arranged so that all values better than the reference are higher values. The lower the value, the more negative the result. This will aid the viewer in seeing that variables closest to the centre are those that need most attention, to enable groups or individuals to be compared to the reference value. All graphs have an age/gender-dependent median value for all variables.

Table 1 lists the chosen variables with reference values and how they are presented.

Table 1. Variables and reference values used in the radar plot.

\begin{tabular}{cccc}
\hline Variable & Unit & Reference Value & Presentation \\
\hline Systolic Blood Pressure & $\mathrm{mmHg}$ & 90 th percentile & Inverted + \\
Waist Circumference & $\mathrm{cm}$ & 90 th percentile & Inverted \\
Waist to Height Ratio & - & 0.50 & Inverted \\
Quality of Life & $\%$ & 100 & Normal \\
Endurance Test & Average/min/day & 90 & Normal \\
Total Cholesterol & $\mathrm{m}$ & 90 th percentile & Normal \\
Moderate to Vigorous Physical Activity & $\mathrm{mmol} / \mathrm{L}$ & 5.2 & Inverted \\
High Density Lipoprotein Concentration & $\mathrm{mmol} / \mathrm{L}$ & 1.5 & Normal \\
\hline
\end{tabular}

+ Inverted means that a low raw score is presented with a high value, and a high raw score with a low value. Since low blood pressure is healthier, the scale is inverted. A high value on the endurance test is preferable, so a high score gives a high value and the scale is normal.

\subsection{Measurements}

\subsubsection{Blood Pressure}

Blood pressure was measured with an Omron M6 IT (Omron Healthcare Co, Ltd, Kyoto, Japan) with the child seated and with the left arm resting on a table. In Norway for children aged 7-12 years, the mean systolic blood pressure was found to be between 95 and $115 \mathrm{mmHg}$, and we use this as a reference for our data [9]. A risk limit may be hard to define in children as blood pressure increases naturally with increasing body mass, increased hydrostatic pressure, and hormone changes. However, we used the highest 90th percentile as cut-off point for each age group and gender. Any value below that would be considered not harmful. For the visual effect, the scale was inverted, so a low value has a high score.

\subsubsection{Waist Circumference}

Waist circumference (WC) was measured according to the WHO STEPS standard where measurements are made at the approximate midpoint between the lower margin of the last palpable rib and the top of the iliac crest after a normal expiration [10]. WC was found to be a better predictor of obesity-related health risk than body mass index (BMI) [11] It is also well established that adiposity around the waist is considered to be more harmful with regard to cardio-metabolic diseases than fat distributed around the body [12] The International Diabetes Federation has suggested using the 90th percentile for children aged 10 to 16 [13] and we have followed this recommendation in our plot.

\subsubsection{Waist to Height Ratio (WHtR)}

The WHtR was calculated as the WC in $\mathrm{cm}$ divided by the height in $\mathrm{cm}$. Height was measured with a portable Seca 213 stadiometer (Seca GmbH, Hamburg, Germany). The subject stood with feet together without shoes, looking straight ahead. Height was recorded to the nearest $0.5 \mathrm{~cm}$. WHtR was found to correlate better with abdominal obesity and cardio-metabolic risk factors than traditional BMI and WC in children [14]. WHtR is considered to be more useful than BMI as it is better at locating 
adiposity, does not involve other tissue, and may be used across age and gender [15]. Against this background, WHtR was chosen to characterise overweight problems in the population, with a cut-off ratio of 0.5 as suggested by [16]. This ratio was proven to correspond relatively well with BMI cut-off ratios with regard to the risk of cardio-metabolic diseases [17]. The scale was inverted to achieve a consistent visual effect.

\subsubsection{Quality of Life (QoL)}

In any health profile, a variable describing an individual's well-being should be included. Self-reported quality of life $(\mathrm{QoL})$ was assessed with the Norwegian version of the Inventory of Life Quality in Children and Adolescents, (ILC) [18]. This is a seven-item inventory that uses 5-point Likert scales to score the answers. Children below 11 years were advised to do the test by interview. We did this by having the children fill out the questionnaire themselves, under supervision. The inventory was given both to children and to parents. The parental score is not presented here. Highest achievable score, 100, was used by us as the reference score. Kristensen and Hove [19] evaluated the internal consistency of the Norwegian version of ILC and found it to be acceptable (Cronbach $\alpha 0.63$. to 0.76). Reliability was found to be good, 0.72 ).

\subsubsection{Blood Samples}

Blood was collected in a nonfasting state during the school day by trained phlebotomists. Blood was drawn from the antecubital vein in $4 \mathrm{~mL}$ serum tubes with a clot activator (Vacuette $囚$, Greiner Bio-One, Kremsmünster, Austria) and analysed in the central laboratory of Vestfold Hospital Trust. Total cholesterol and HDL cholesterol were analysed on Vitros 5.1 (Ortho-Clinical Diagnostics, Franklin, Raritan, NJ, USA) with reagents from the supplier.

\subsubsection{Serum Cholesterol}

The American Academy of Pediatrics defines serum cholesterol above $5.2 \mathrm{mmol}$ as pathological for children aged 6-12 [20]. Here, values lower than 5.2 are displayed as higher values on the radar diagram.

\subsubsection{High Density Lipoprotein (HDL)}

High levels of HDL were shown to correspond with reduced risk of cardiovascular diseases in adults. By extrapolation, it is thought that high values are preferable also in children. The American Academy of Pediatrics suggests a value above $1.66 \mathrm{mmol} / \mathrm{L}$ to be "acceptable" and below 1.04 to be "low" [21], but there is no national or international consensus regarding a preferred and clinically positive cut-off value for HDL. The reference value in this diagram is $1.5 \mathrm{mmol} / \mathrm{L}$. Hence, higher values are positive.

\subsubsection{Physical Activity (PA)}

The level of physical activity was monitored by Actigraph wGT3X-BT accelerometers (ActiGraph LLC, Pensacola, FL, USA). Participants were instructed to attach the device to the right side of their hip with an elastic band for seven consecutive days, at all hours, unless injured, ill, showering, swimming, or absent from school on the day of testing. A detailed description of the accelerometer recordings is given in [22]. PA levels were based on mean counts per minute (cpm) with 0-99 cpm as sedentary, 100-1999 cpm light, 2000-4999 cpm moderate, and $\geq 5000 \mathrm{cpm}$ vigorous. The traditional minimal standard given for children is $60 \mathrm{~min}$ of PA a day, but it was suggested that $90 \mathrm{~min}$ a day with a moderate to vigorous intensity level would be a better goal [23]. The reference value was therefore set to $90 \mathrm{~min}$ a day. 


\subsubsection{Endurance Test}

Several studies have shown that enhanced aerobic fitness may be a significant contributor in reducing the risk of acquiring cardio-metabolic diseases in both children [24] and adults [23]. Several shuttle run tests exist, but the Andersen interval shuttle run test [25] was especially developed and designed for children. In the Andersen test, the participants perform a shuttle run between two cones $20 \mathrm{~m}$ apart at self-selected pace for $15 \mathrm{~s}$, then rest for $15 \mathrm{~s}$ and continue the test for $10 \mathrm{~min}$. The distance covered is used here as the performance criterion. The test was found valid and with an acceptable reliability for 10-year-old children [26]. The 90th percentile for each age group was used as reference value. Hence the higher the value, the better protected the child was against cardio-metabolic diseases.

\subsection{Statistics}

Results are presented as mean (SD) unless otherwise stated. The radar graphs present the median of each age-gender group. As reference, either age-gender specific values, generally accepted cut-off values, or normative data were used; see Table 1 for details. Independent groups were compared with Gosset (Student) t-test. The statistical software used included IBM SPSS v. 25 (IBM, Armonk, NJ, USA) and SigmaPlot v. 14 (Systat Software, GmbH., Erkrath, Germany).

\section{Results}

\section{Basic Results}

Height and body mass increased normally with age, as 6th graders were $29 \mathrm{~cm}$ taller than $1 \mathrm{st}$ graders and weighed $18.7 \mathrm{~kg}$ more. WHtR did not change and was between 0.44 and 0.47 across the age span. WC increased by $9.9 \mathrm{~cm}$ across age for girls and by $11.9 \mathrm{~cm}$ for boys. The increase in systolic blood pressure was slightly smaller among girls, but values were within the normal range.

The concentration of HDL was significantly higher in boys across age $(\mathrm{p}<0.05)$, compared with girls. On the other hand, total cholesterol values did not differ much between the genders or age groups.

Physical activity, measured as moderate to vigorous physical activity (MVPA), showed typical gender and age development, with boys having higher scores and with a decrease in activity level with increasing age for both genders. MVPA decreased by $18 \mathrm{~min}$ a day from 1st to 6th grade for boys and by $20 \mathrm{~min}$ for girls. Endurance performance, measured using the Andersen interval shuttle run test, showed that boys ran farther than girls did in all age groups. The biggest average difference was in 6th grade, at $41 \mathrm{~m}$. The increase in maximal running distance developed rather linearly with age, but between $3 \mathrm{rd}$ and 4 th grade, the development plateaued for girls. For boys, running distance increased by $49 \pm 27 \mathrm{~m} \cdot$ year $^{-1}$ and for girls by $45 \pm 25 \mathrm{~m} \cdot$ year $^{-1}$. With regard to quality of life, the children seemed quite satisfied as both genders revealed a small, but statistically significant, increase in well-being across grades: see Table 2 .

In Figure 1, the children scored below reference values on systolic blood pressure and the Andersen Test. This is because the reference values are the 90th percentile, and the scores are the median value. For the variables that use a fixed reference value: HDL, total cholesterol, MVPA, and quality of life, the scores were often better than the reference. The radar graph makes it easy to pinpoint specific variables and how the scoring of these relates to the reference and also to detect gender differences.

Table 2. Values for each age group sorted by gender.

\begin{tabular}{cccccccc}
\hline \multirow{2}{*}{ Grade } & & \multicolumn{2}{c}{ Girls } & $\mathbf{3}$ & $\mathbf{4}$ & $\mathbf{5}$ & $\mathbf{6}$ \\
\hline \multirow{3}{*}{ Height $(\mathrm{m})$} & mean & 1.24 & 1.29 & 1.34 & 1.40 & 1.47 & 1.53 \\
& SD & 0.06 & 0.06 & 0.06 & 0.07 & 0.08 & 0.08 \\
& 10th percentile & 1.16 & 1.22 & 1.27 & 1.31 & 1.37 & 1.42 \\
& 90th percentile & 1.30 & 1.37 & 1.42 & 1.48 & 1.57 & 1.62 \\
\hline
\end{tabular}


Table 2. Cont

\begin{tabular}{|c|c|c|c|c|c|c|c|}
\hline \multicolumn{8}{|c|}{ Girls } \\
\hline Grade & & 1 & 2 & 3 & 4 & 5 & 6 \\
\hline \multirow{4}{*}{ Body Mass (kg) } & mean & 24.3 & 26.8 & 30.2 & 33.7 & 38.3 & 43.0 \\
\hline & SD & 4.8 & 5.3 & 6.0 & 8.0 & 8.7 & 9.8 \\
\hline & 10th percentile & 19.2 & 21.5 & 23.1 & 25.8 & 29.3 & 32.3 \\
\hline & 90th percentile & 30.0 & 33.5 & 37.1 & 44.0 & 50.2 & 56.2 \\
\hline \multirow{4}{*}{ WHtR } & mean & 0.47 & 0.46 & 0.46 & 0.45 & 0.45 & 0.44 \\
\hline & $\mathrm{SD}$ & 0.04 & 0.04 & 0.04 & 0.05 & 0.05 & 0.06 \\
\hline & 90th percentile & 0.42 & 0.42 & 0.41 & 0.39 & 0.40 & 0.39 \\
\hline & 10th percentile & 0.53 & 0.52 & 0.51 & 0.50 & 0.51 & 0.52 \\
\hline \multirow{4}{*}{$\mathrm{WC}(\mathrm{cm})$} & mean & 57.8 & 59.3 & 61.5 & 63.0 & 65.5 & 67.7 \\
\hline & SD & 6.2 & 5.9 & 6.6 & 8.6 & 8.1 & 9.0 \\
\hline & 90th percentile & 51.1 & 54.0 & 54.0 & 54.0 & 57.6 & 59.0 \\
\hline & 10th percentile & 66.0 & 67.1 & 70.0 & 72.7 & 75.5 & 79.0 \\
\hline \multirow{4}{*}{ SBP (mmHg) } & mean & 104 & 106 & 107 & 108 & 111 & 112 \\
\hline & SD & 10 & 11 & 10 & 11 & 10 & 11 \\
\hline & 90th percentile & 92 & 92 & 96 & 96 & 100 & 98.3 \\
\hline & 10th percentile & 117 & 119 & 121 & 122 & 123 & 125.0 \\
\hline \multirow{4}{*}{$\mathrm{HDL}(\mathrm{mmol} / \mathrm{L})$} & mean & 1.54 & 1.63 & 1.56 & 1.56 & 1.59 & 1.57 \\
\hline & SD & 0.33 & 0.36 & 0.33 & 0.33 & 0.34 & 0.32 \\
\hline & 10th percentile & 1.10 & 1.1 & 1.20 & 1.20 & 1.16 & 1.20 \\
\hline & 90th percentile & 2.03 & 2.1 & 2.00 & 2.00 & 2.00 & 2.00 \\
\hline \multirow{4}{*}{ Tot Chol (mmol/L) } & mean & 4.31 & 4.27 & 4.33 & 4.55 & 4.38 & 4.26 \\
\hline & $\mathrm{SD}$ & 0.64 & 0.66 & 0.71 & 0.69 & 0.69 & 0.64 \\
\hline & 90th percentile & 3.60 & 3.50 & 3.50 & 3.60 & 3.50 & 3.50 \\
\hline & 10th percentile & 5.10 & 5.20 & 5.19 & 5.53 & 5.30 & 5.20 \\
\hline \multirow{4}{*}{ Andersen Test (m) } & mean & 779 & 855 & 934 & 934 & 975 & 1022 \\
\hline & SD & 121 & 104 & 127 & 116 & 101 & 112 \\
\hline & 10th percentile & 610 & 715 & 790 & 797 & 843 & 890 \\
\hline & 90th percentile & 949 & 982 & 1085 & 1078 & 1125 & 1155 \\
\hline \multirow{4}{*}{ MVPA (min) } & mean & 98 & 91 & 91 & 79 & 79 & 78 \\
\hline & SD & 26 & 26 & 26 & 25 & 28 & 24 \\
\hline & 10th percentile & 64 & 57 & 60 & 50.2 & 46 & 47 \\
\hline & 90th percentile & 132 & 126 & 128 & 113 & 120 & 113 \\
\hline \multirow{4}{*}{ QoL (\%) } & mean & 80.8 & 81.7 & 83.3 & 84.2 & 85.4 & 85.3 \\
\hline & SD & 11.8 & 10.2 & 11.5 & 9.2 & 9.5 & 10.7 \\
\hline & 10th percentile & 64.3 & 67.9 & 67.9 & 71.4 & 71.4 & 71.4 \\
\hline & 90th percentile & 96.4 & 96.4 & 96.4 & 96.4 & 96.4 & 96.4 \\
\hline \multicolumn{8}{|c|}{ Boys } \\
\hline Grade & & 1 & 2 & 3 & 4 & 5 & 6 \\
\hline \multirow{4}{*}{ Height (m) } & mean & 1.24 & 1.30 & 1.36 & 1.41 & 1.47 & 1.53 \\
\hline & $\mathrm{SD}$ & 0.06 & 0.06 & 0.06 & 0.06 & 0.08 & 0.08 \\
\hline & 10th percentile & 1.16 & 1.23 & 1.29 & 1.33 & 1.37 & 1.42 \\
\hline & 90th percentile & 1.31 & 1.38 & 1.44 & 1.49 & 1.57 & 1.62 \\
\hline \multirow{4}{*}{ Body Mass (kg) } & mean & 23.8 & 27.3 & 31.1 & 35.0 & 39.0 & 42.5 \\
\hline & SD & 4.3 & 4.1 & 5.8 & 6.9 & 8.0 & 8.5 \\
\hline & 10th percentile & 19.4 & 22.7 & 25.0 & 27.3 & 30.9 & 33.3 \\
\hline & 90th percentile & 29.4 & 33.1 & 37.6 & 45.2 & 49.8 & 54.2 \\
\hline \multirow{4}{*}{ WHtR } & mean & 0.46 & 0.46 & 0.45 & 0.46 & 0.46 & 0.45 \\
\hline & SD & 0.03 & 0.04 & 0.04 & 0.04 & 0.06 & 0.05 \\
\hline & 90th percentile & 0.42 & 0.43 & 0.41 & 0.39 & 0.41 & 0.40 \\
\hline & 10th percentile & 0.50 & 0.51 & 0.52 & 0.50 & 0.54 & 0.51 \\
\hline
\end{tabular}


Table 2. Cont.

\begin{tabular}{|c|c|c|c|c|c|c|c|}
\hline \multicolumn{8}{|c|}{ Girls } \\
\hline Grade & & 1 & 2 & 3 & 4 & 5 & 6 \\
\hline \multirow{4}{*}{$\mathrm{WC}(\mathrm{cm})$} & mean & 56.9 & 59.9 & 61.5 & 64.5 & 67.1 & 68.8 \\
\hline & SD & 5.0 & 5.3 & 6.6 & 7.4 & 8.4 & 8.0 \\
\hline & 90th percentile & 51.1 & 54.5 & 54.0 & 56.5 & 59.0 & 60.0 \\
\hline & 10th percentile & 63.0 & 67.0 & 70.0 & 75.0 & 79.0 & 80.0 \\
\hline \multirow{4}{*}{$\mathrm{SBP}(\mathrm{mmHg})$} & mean & 104 & 107 & 110 & 109 & 112 & 113 \\
\hline & SD & 9 & 10 & 9 & 10 & 9 & 11 \\
\hline & 90th percentile & 93 & 95 & 98 & 98 & 100 & 98 \\
\hline & 10th percentile & 116 & 118 & 122 & 120 & 123 & 127 \\
\hline \multirow{4}{*}{ HDL (mmol/L) } & mean & 1.67 & 1.71 & 1.71 & 1.70 & 1.62 & 1.66 \\
\hline & SD & 0.39 & 0.35 & 0.37 & 0.33 & 0.36 & 0.35 \\
\hline & 10th percentile & 1.25 & 1.24 & 1.20 & 1.30 & 1.20 & 1.20 \\
\hline & 90th percentile & 2.25 & 2.10 & 2.30 & 2.10 & 2.10 & 2.10 \\
\hline \multirow{4}{*}{ Tot Chol (mmol/L) } & mean & 4.31 & 4.24 & 4.33 & 4.30 & 4.30 & 4.24 \\
\hline & $\mathrm{SD}$ & 0.66 & 0.59 & 0.71 & 0.65 & 0.586 & 0.634 \\
\hline & 90th percentile & 3.40 & 3.60 & 3.50 & 3.46 & 3.60 & 3.50 \\
\hline & 10th percentile & 4.90 & 5.06 & 5.19 & 5.04 & 5.20 & 5.00 \\
\hline \multirow{4}{*}{ Andersen Test (m) } & mean & 806 & 870 & 966 & 995 & 1009 & 1063 \\
\hline & SD & 112 & 118 & 126 & 132 & 120 & 111 \\
\hline & 10th percentile & 641 & 740 & 790 & 849 & 840 & 915 \\
\hline & 90th percentile & 949 & 1014 & 1116 & 1160 & 1160 & 1215 \\
\hline \multirow{4}{*}{ MVPA (min) } & mean & 106 & 98 & 102 & 92 & 89 & 88 \\
\hline & $\mathrm{SD}$ & 26 & 26 & 28 & 29 & 30 & 28 \\
\hline & 10th percentile & 73 & 65 & 67 & 76 & 54 & 57 \\
\hline & 90th percentile & 136 & 135 & 139 & 135 & 130 & 128 \\
\hline \multirow{4}{*}{ QoL (\%) } & mean & 81.0 & 81.1 & 83.7 & 86.0 & 86.0 & 86.0 \\
\hline & SD & 13.08 & 13.0 & 9.9 & 9.3 & 9.3 & 9.3 \\
\hline & 10th percentile & 62.93 & 64.3 & 70.4 & 75.0 & 75.0 & 75.0 \\
\hline & 90th percentile & 97.9 & 96.4 & 96.4 & 96.4 & 96.4 & 96.4 \\
\hline
\end{tabular}

WHtR = Waist-to-Height Ratio, WC = Waist Circumference, SBP = Systolic Blood Pressure, Tot Chol = Total Cholesterol, MVPA = Moderate to Vigorous Physical Activity, QoL = Quality of Life.
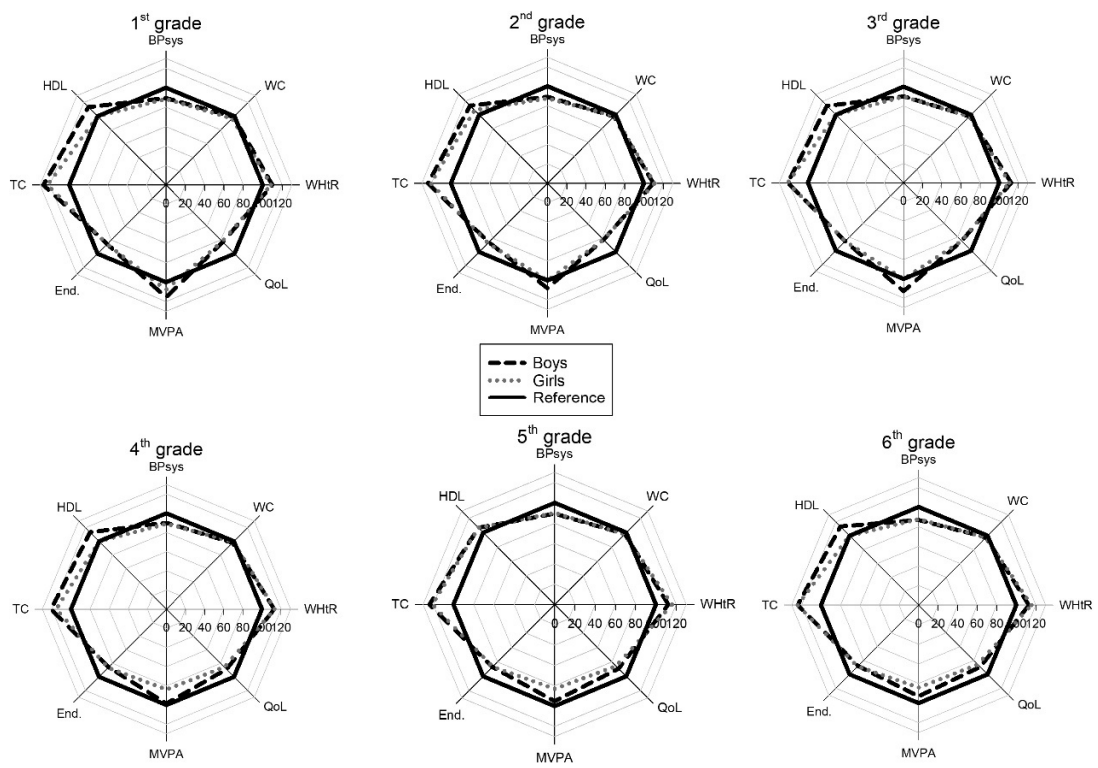

Figure 1. Health profiles for boys and girls from 1st to 6th grade. The higher the score, the healthier the value. WHtR = Waist to Height Ratio, MVPA = Moderate to Vigorous Physical Activity, Tot Chol $=$ Total Cholesterol, HDL = High Density Lipoproteins. 
Figure 2 shows two cases of children considered to be at risk for future cardiovascular disease. They both score well below their classmates' values and the reference line on several of the variables. The plot provides an easily interpretable view of the reduced health score of these individuals.
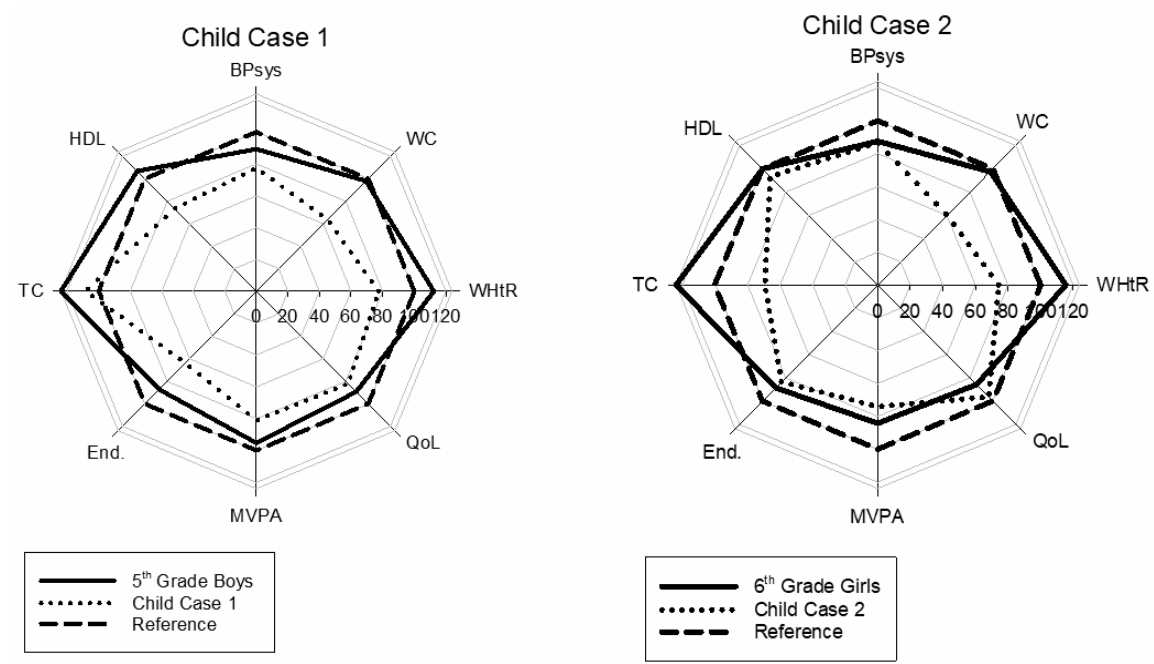

Figure 2. Two child cases to illustrate the health profile. Legends as in Figure 1.

\section{Discussion}

\subsection{Main Findings}

The children from the HOPP study appear to be of good, normal health both physiological and mental. The most worrying factor may be the significant decline in physical activity level as age increases. On the positive side were the blood tests, where the values were consistently better than the Norwegian reference values. A radar graph made it easy to visualise the overall health status for both groups and individual cases.

\subsection{Choice of Variables}

The HOPP project produces a plethora of variables and selecting significant variables to represent a suitable health profile proved difficult. Not all variables were measured in all age categories in the HOPP project. Our choice of variables was therefore based on measurements performed on all age groups and based on the theoretical and empirical explanatory strength of each variable on health. Most variables concerning children's lifestyle-related risk factors are based on an extrapolation from adulthood. The variables should thus only be seen as risk factors for future probability of illness or disease and not as definitive endpoints with regard to children, as not all factors are traceable into adulthood. There is an ongoing concern regarding disagreement about risk factor determinants. This hampers comparison across scientific findings, thus making it difficult to draw conclusions about the epidemiological situation [27]. Paediatric cut-off values are generally problematic and questionable as their future health consequences are poorly validated. Definitions of paediatric risk factors should therefore be applied with caution. However, some longitudinal studies have revealed that classification of childhood risk factors does predict adult metabolic syndrome and type 2 diabetes [28].

\subsection{Anthropometric Variables}

Table 1 displays the chosen anthropological variables from grade 1 to 6 for both sexes. The development was normal for height and body mass, as we presented earlier [29]. WHtR did not change over time in either boys or girls. No clear trend was seen, and the largest change was only 0.03 , for girls in first grade $(\mathrm{WHtR}=0.47)$ to sixth grade $(\mathrm{WHtR}=0.44)$. This would indicate that obesity problems were not a serious issue in the cohort, as Zhou et al. found WHtR to be a simple 
and practical screening tool for obesity and metabolic syndrome in children [30]. Letho et al. found both WC and WHtR to be associated with children's health behaviour [31]. We found a significant correlation between average MVPA and WHtR ( $p=0.049$, not shown), but the significance is due to a large $\mathrm{N}$. On a grade/gender level, boys in 5th grade had the highest correlation, with $\mathrm{r}=0.22$, which corresponds to a small effect size. One should also be critical of the accuracy of WHtR to detect health status. Sardinha et al. found low precision for WHtR and BMI to classify increased CVD risk [32]. Further, Keefer et al. could not find an association between systolic blood pressure, total cholesterol, and WHtR for the young segment of the National Health and Nutrition Examination Survey (NHANES) cohort but found a significant association in the entire cohort [33]. This weakness of single variables to predict CVD health is an important argument for using a carefully selected blend of variables for risk determination.

\subsection{Medical Variables}

Blood pressure is by nature difficult to measure due to its large variability caused by movement during measuring, disturbances catching the children's attention, emotional variability of any kind, and PA of high intensity prior to measurement. The latter was avoided by placing restrictions on PA two hours prior to blood pressure testing. Usually blood pressure is measured three times and the mean value is used. In the present study, this was not possible; however, the mean systolic blood pressure values are still within the normal range. The systolic blood pressure (SBP) was within the normal range for Norwegian children for both sexes and all age groups. The increase seen from first to sixth grade does not deviate much from reference data of Norwegian children [34]. All children with initial high systolic blood pressure values were retested about four weeks later, and no child was found with pathological values requiring treatment. The reason for using systolic and not diastolic is the large variability and uncertainty in the measurement of diastolic blood pressure. It is unusual for children to have high blood pressure, which might suggest that a persistent high reading in a child is significant and a clear indication for treatment with nutrition changes and increased PA, or in some cases, antihypertension medication.

\subsubsection{HDL}

The HDL concentration did not differ across age but it did between genders. One reason might be that the higher PA level in boys has a positive influence on HDL concentration, as was found in other studies [35]. If so, the reduced levels of PA observed with age are a cause for concern.

\subsubsection{Total Cholesterol}

Studies have established atherosclerosis in children as young as two years old, and an elevated level of serum cholesterol may increase the risk of further development of the disease [36]. The present results show normal values, however, Strand et al. showed in a previous paper from the HOPP study that some children do display high values [37]. Approximately $7 \%$ of the children in the present study had values above $5.2 \mathrm{mmol} / \mathrm{L}$, which is considered pathological [38]. No statistical differences were found between total cholesterol levels and sex, except for girls in 2nd and 4th grade who had 4.27 $(0.66)$ vs. $4.55(0.69) \mathrm{mmol} / \mathrm{L}$ respectively $(\mathrm{p}=0.04)$. How much this difference matters for future cardiovascular health is uncertain. The effect size is 0.41 , indicating low clinical value.

\subsection{Activity Level}

\section{MVPA}

A high physical activity level as a child may track positively into adulthood [39]. It is therefore important to maintain a high activity level in children throughout childhood, by engaging them in motivating activities, such as play and games. The reduction in activity level was substantial for both boys and girls, with 18 and 20 min reduced time in MVPA from 1st to 6th grade, which corresponds 
to a $20 \%$ decrease in activity. Only 1st-4th grade boys and 1st-3rd year girls had MVPA above the recommended $90 \mathrm{~min}$ a day [24]. The reduction in activity seen when using accelerometers might also include measurement bias, as height increases with age, increasing the time of each leg movement, and thus less movement is recorded. In addition, from an energy expenditure point of view, it may be difficult to compare young and older children, as their increase in body mass will make it more demanding to move a larger body [40]. In addition, longer legs are like a longer pendulum, and thus reduce acceleration and give lower values [21]. Hence, even if accelerometer readings show a decline, this may not affect energy expenditure to the same degree.

\subsection{Endurance Performance}

As expected, running performance on the Andersen Test increased with age. Compared with the values for 10-year-old children in the study by Aadland et al. [26], our results are significantly better for the 5th graders. For boys this difference was 35 (16.5) $\mathrm{m}, \mathrm{p}=0.04$, while for girls it was 66 (14.5) $\mathrm{m}, p<0.01$. It may be difficult to make valid comparisons between measurements taken at different locations. The results of the HOPP study are a blend of results from nine different schools, which all have different surfaces to run on. Further, the HOPP study used different data collectors on the schools and the children had no identification number on them when running. Misclassifications may thus be a source of error and may partly explain the observed difference.

\subsection{Quality of Life}

Quality of life is considered an important variable for evaluating the overall health status of a child. Low scores on quality of life may represent a significant threat to child and adolescent health and may cause physiological problems and vice versa. Scores from the present study on life quality were high, indicating that these children have a good life. The score steadily increased a little year by year and the scores in first grade were statistically lower than the 4th to 6th grade scores for both boys and girls.

Despite being overweight and in poor health, the girl used as an example in Figure 2 scored high on quality of life, better than the median of her group. Even though many children experience negative feedback and cultural stigma due to overweight and poor physical health, life quality for this girl is evidently more than just physical health. This is a good illustration of the need for "softer data" in a health profile.

\subsection{Strengths and Limitations}

The strengths of this study are the large number of participants and the high number of carefully chosen variables collected. The weaknesses are the large number of persons that took part in the data collection and the use of some self-report data from children.

\section{Conclusions}

The investigated population was generally in good CVD health. A radar plot was feasible to display a large number of health-related variables in a child population. The plot was useful in displaying both group data and cases. The presentation with a radar plot can help to identify children, or groups, in need of early intervention and may be used to investigate health tracking through childhood to adolescents and adulthood. If such a presentation is found useful, an expert panel should decide which variables and reference values should be used, any weighting of variables, and how the data should be presented. 
Author Contributions: Conceptualization, P.M.F. and A.M.; methodology, A.M.; software, A.M.; validation, P.M.F., L.E.B. and A.M.; formal analysis, P.M.F., and A.M.; investigation, P.M.F., L.E.B., A.M.; data curation, A.M.; writing—original draft preparation, A.M.; writing—review and editing, P.M.F., L.E.B., A.M.; All authors have read and agreed to the published version of the manuscript.

Funding: This research received no external funding.

Conflicts of Interest: The authors declare no conflict of interest.

\section{References}

1. Berenson, G.S.; Wattigney, W.A.; Tracy, R.E.; Newman, W.P.; Srinivasan, S.R.; Webber, L.S.; Dalferes, E.R.; Strong, J.P. Atherosclerosis of the aorta and coronary arteries and cardiovascular risk factors in persons aged 6 to 30 years and studied at necropsy (the Bogalusa Heart Study). Am. J. Cardiol. 1992, 70, 851-858. [CrossRef]

2. Kopf, E.W. Florence Nightingale as Statistician. Publ. Am. Stat. Assoc. 1916, 15, 388-404. [CrossRef]

3. Friendly, M.; Denis, D.J. Milestones in the History of Thematic Cartography, Statistica 1 Graphics, and Data Visualization. Available online: https://www.researchgate.net/publication/240118128_Milestones_in_the_ history_of_thematic_cartography_statistica_1_graphics_and_data_visualization (accessed on 11 April 2020).

4. Noirhomme-Fraiture, M. Visualization of Large Data Sets: The Zoom Star Solution. Available online: https://www.semanticscholar.org/paper/Visualization-of-Large-Data-Sets\%3A-The-Zoom-StarNoirhomme-Fraiture/2d9240bde13b1707b20b02759eb0726e4b409fcd (accessed on 14 April 2020).

5. Radar Chart-Minnesota Department of Health. Available online: https://www.health.state.mn.us/ communities/practice/resources/phqitoolbox/radarchart.html\#sources (accessed on 14 April 2020).

6. Ordóñez, P.; desJardins, M.; Lombardi, M.; Lehmann, C.U.; Fackler, J.C. An animated multivariate visualization for physiological and clinical data in the ICU. In Proceedings of the IHI; ACM: Arlington, VA, USA, 2010.

7. Aasland, O.G. Alkohol og EU—fri flyt? Alcohol and EU—free flow? Tidsskr. Den. Nor. Legeforening 2003, 123, 188-189.

8. Fredriksen, P.M.; Hjelle, O.P.; Mamen, A.; Meza, T.J.; Westerberg, A.C. The health Oriented pedagogical project (HOPP)—A controlled longitudinal school-based physical activity intervention program. BMC Public Health 2017, 17, 370. [CrossRef]

9. Norsk Barnelegeforening Pediatriveiledere fra Norsk barnelegeforening Pediatric Guidence from Norwegian Pediatrician Association in Norwegian. Available online: /pediatriveiledere?key=181604\& menuitemkeylev1=6747\&menuitemkeylev2=6507 (accessed on 18 March 2020).

10. WHO. WHO | Waist Circumference and Waist-Hip Ratio; World Health Organization: Geneva, Switzerland, 2008 ; p. 47.

11. Janssen, I.; Katzmarzyk, P.T.; Ross, R. Waist circumference and not body mass index explains obesity-related health risk. Am. J. Clin. Nutr. 2004, 79, 379-384. [CrossRef]

12. Bays, H.E.; Toth, P.P.; Kris-Etherton, P.M.; Abate, N.; Aronne, L.J.; Brown, W.V.; Gonzalez-Campoy, J.M.; Jones, S.R.; Kumar, R.; La Forge, R.; et al. Obesity, adiposity, and dyslipidemia: A consensus statement from the National Lipid Association. J. Clin. Lipidol. 2013, 7, 304-383. [CrossRef]

13. International Diabetes Federation. The IDF Consensus Definition of the Metabolic Syndrome in Children and Asolescents; International Diabetes Federation: Brussels, Belgium, 2007; p. 24.

14. Seo, J.-Y.; Kim, J.H. Validation of surrogate markers for metabolic syndrome and cardiometabolic risk factor clustering in children and adolescents: A nationwide population-based study. PLoS ONE 2017, 12. [CrossRef]

15. Ashwell, M.; Hsieh, S.D. Six reasons why the waist-to-height ratio is a rapid and effective global indicator for health risks of obesity and how its use could simplify the international public health message on obesity. Int. J. Food Sci. Nutr. 2005, 56, 303-307. [CrossRef]

16. Browning, L.M.; Hsieh, S.D.; Ashwell, M. A systematic review of waist-to-height ratio as a screening tool for the prediction of cardiovascular disease and diabetes: 0.5 could be a suitable global boundary value. Nutr. Res. Rev. 2010, 23, 247-269. [CrossRef]

17. Swainson, M.G.; Batterham, A.M.; Tsakirides, C.; Rutherford, Z.H.; Hind, K. Prediction of whole-body fat percentage and visceral adipose tissue mass from five anthropometric variables. PLoS ONE 2017, 12, e0177175. [CrossRef] 
18. Högrefe Psykologiförlaget Inventory of Life Quality in Children and Adolescents. Available online: https://www.hogrefe.no/Klinisk-psykologi/Personlighetstester/ILC/ (accessed on 5 August 2019).

19. Kristiansen, H.; Hove, P. Måleegenskaper ved den norske versjonen av The Inventory of Life Quality in children and adolescents (ILC) [Measurement properties of the Norwegian version of ... ]. PsykTestBarn 2013, 1, 1-9. [CrossRef]

20. American Academy of Pediatrics, Committee on Nutrition. Cholesterol in childhood. Pediatrics 2011, 128, S213-S256. [CrossRef]

21. Deng, W.H.; Fredriksen, P.M. Objectively assessed moderate-to-vigorous physical activity levels among primary school children in Norway: The Health Oriented Pedagogical Project (HOPP). Scand. J. Public Health 2018, 46, 38-47. [CrossRef] [PubMed]

22. American Academy of Pediatrics. Committee on Nutrition American Academy of Pediatrics. Committee on Nutrition. Cholesterol in childhood. Pediatrics 1998, 101, 141-147.

23. Paffenbarger, R.S.; Hyde, R.T.; Wing, A.L.; Hsieh, C.C. Physical activity, all-cause mortality, and longevity of college alumni. N. Engl. J. Med. 1986, 314, 605-613. [CrossRef] [PubMed]

24. Andersen, L.; Harro, M.; Sardinha, L.; Froberg, K.; Ekelund, U.; Brage, S.; Anderssen, S. Physical activity and clustered cardiovascular risk in children: A cross-sectional study (The European Youth Heart Study). Lancet Lond. Engl. 2006, 368, 299-304. [CrossRef]

25. Andersen, L.B.; Andersen, T.E.; Andersen, E.; Anderssen, S.A. An intermittent running test to estimate maximal oxygen uptake: The Andersen test. J. Sports Med. Phys. Fit. 2008, 48, 434-437.

26. Aadland, E.; Kvalheim, O.M.; Anderssen, S.A.; Resaland, G.K.; Andersen, L.B. The multivariate physical activity signature associated with metabolic health in children. Int. J. Behav. Nutr. Phys. Act. 2018. [CrossRef]

27. Brambilla, P.; Lissau, I.; Flodmark, C.-E.; Moreno, L.A.; Widhalm, K.; Wabitsch, M.; Pietrobelli, A. Metabolic risk-factor clustering estimation in children: To draw a line across pediatric metabolic syndrome. Int. J. Obes. 2007, 31, 591-600. [CrossRef]

28. Morrison, J.A.; Friedman, L.A.; Wang, P.; Glueck, C.J. Metabolic Syndrome in Childhood Predicts Adult Metabolic Syndrome and Type 2 Diabetes Mellitus 25 to 30 Years Later. J. Pediatr. 2008, 152, 201-206. [CrossRef]

29. Skår, A.; Meza, T.J.; Fredriksen, P.M. Development of weight and height in Norwegian children: The Health Oriented Pedagogical Project (HOPP). Scand. J. Public Health 2018, 46, 3-11. [CrossRef] [PubMed]

30. Zhou, D.; Yang, M.; Yuan, Z.-P.; Zhang, D.-D.; Liang, L.; Wang, C.-L.; Zhang, S.; Zhu, H.-H.; Lai, M.-D.; Zhu, Y.-M. Waist-to-Height Ratio: A simple, effective and practical screening tool for childhood obesity and metabolic syndrome. Prev. Med. 2014, 67, 35-40. [CrossRef] [PubMed]

31. Lehto, R.; Ray, C.; Lahti-Koski, M.; Roos, E. Health behaviors, waist circumference and waist-to-height ratio in children. Eur. J. Clin. Nutr. 2011, 65, 841-848. [CrossRef]

32. Sardinha, L.B.; Santos, D.A.; Silva, A.M.; Grøntvedt, A.; Andersen, L.B.; Ekelund, U. A comparison between BMI, waist circumference, and waist-to-height ratio for identifying cardio-metabolic risk in children and adolescents. PLoS ONE 2016. [CrossRef] [PubMed]

33. Keefer, D.J.; Caputo, J.L.; Tseh, W. Waist-to-Height Ratio and Body Mass Index as Indicators of Cardiovascular Risk in Youth. J. Sch. Health 2013, 83, 805-809. [CrossRef] [PubMed]

34. St. Olavs Hospital, B.- og ungdomspsykiatrisk klinikk Hva_er_normalt_blodtrykk_hos_barn? What's Normal Blood Pressure for Children? Available online: http://onlinelibrary.wiley.com.ezproxy.hio.no/doi/10. 1111/j.1600-0838.2009.01028.x/abstract (accessed on 9 January 2020).

35. Twisk, J.W.; Kemper, H.C.; Van, W.M. Tracking of activity and fitness and the relationship with cardiovascular disease risk factors. Med. Sci. Sports Exerc. 2000, 32, 1455-1461. [CrossRef]

36. Cote, A.T.; Harris, K.C.; Panagiotopoulos, C.; Sandor, G.G.S.; Devlin, A.M. Childhood Obesity and Cardiovascular Dysfunction. J. Am. Coll. Cardiol. 2013, 62, 1309-1319. [CrossRef]

37. Strand, M.F.; Fredriksen, P.M.; Hjelle, O.P.; Lindberg, M. Reference intervals for serum lipids and prevalence of dyslipidaemia in 6-12-year-old children: The Health Oriented Pedagogical Project (HOPP). Scand. J. Public Health 2018, 46, 21-27. [CrossRef]

38. Skinner, A.C.; Steiner, M.J.; Chung, A.E.; Perrin, E.M. Cholesterol Curves to Identify Population Norms by Age and Sex in Healthy Weight Children. Clin. Pediatr. 2012, 51, 233-237. [CrossRef] 
39. Telama, R.; Yang, X.; Leskinen, E.; Kankaanpää, A.; Hirvensalo, M.; Tammelin, T.; Viikari, J.; Raitakari, O. Tracking of Physical Activity from Early Childhood through Youth into Adulthood. Med. Sci. Sports Exerc. 2014, 46, 955-962. [CrossRef]

40. Arvidsson, D.; Fridolfsson, J.; Buck, C.; Ekblom, Ö.; Ekblom-Bak, E.; Lissner, L.; Hunsberger, M.; Börjesson, M. Reexamination of Accelerometer Calibration with Energy Expenditure as Criterion: VO2net Instead of MET for Age-Equivalent Physical Activity Intensity. Sensors 2019, 19, 3377. [CrossRef] [PubMed]

(C) 2020 by the authors. Licensee MDPI, Basel, Switzerland. This article is an open access article distributed under the terms and conditions of the Creative Commons Attribution (CC BY) license (http://creativecommons.org/licenses/by/4.0/). 